The final, definitive version of this paper has been published in Journal of Cellular Plastics, 47/1, January/2011 pp. 45-63 by SAGE Publications Ltd. All rights reserved. @ SAGE Publications Ltd 2011 http://cel.sagepub.com/content/47/1/45.short

\title{
Low Velocity Impact on Polymeric Foams
}

\author{
E.A. Flores-Johnson and Q.M. Li* \\ School of Mechanical, Aerospace and Civil Engineering \\ The University of Manchester, Pariser Building, PO Box 88, Manchester M60 1QD, UK
}

\begin{abstract}
The effect of the impactor nose shape on the penetration behaviour of polymethacrylimide (PMI) foams is investigated in the velocity range of 4-8 m/s. It is observed from experimental results that penetration load depends on the geometry of the impactor and the density of the foam. An analytical model is developed to predict the penetration behaviour of polymeric foams with good agreements between analytical predictions and experimental data.
\end{abstract}

Keywords: Penetration, indentation, low velocity impact, polymeric foam, nose shape effect

*Corresponding author, Email: qingming.li@manchester.ac.uk 


\section{INTRODUCTION}

Rigid polymeric foams are widely used as core material for sandwich constructions in the automotive and aerospace industries because of their light weight and high stiffness. They are also used in non-structural applications, e.g. cushioning, packaging and isolating, because of their energy absorbing properties and good capabilities in vibration and acoustic attenuations. During the service life of foams or foam cored structures, impacts by foreign objects are likely to occur due to various accidental and operational causes [1]. Consequently, a good understanding of impact response of both sandwich structures and foam cores should be addressed in order to predict and assess the damage. It has been shown that low velocity impact is potentially dangerous because the internal damage caused by low velocity impact can be undetected or underestimated, which may grow under service load and cause large reductions in strength, and therefore, a decrease in its structural performance and structural failure.

Polymethacrylimide (PMI) closed-cell rigid foams (trade name Rohacell series [2]) have been widely used in aerospace, automotive, marine and aircraft structures applications. They have been studied for their compressive properties ( $\mathrm{Li}$ et al. [3, 4]) and progressively crushing deformation mechanisms (Li and Mines [5] and Flores-Johnson et al. [6]). Impact properties of sandwich panels with PMI foam cores were reported in Sun and Wu [7] and Rizov et al. [8] while the cell structure of PMI foams and its influence on macroscopic properties were reported in Chen et al. [9] and Chen and Lakes [10].

Although substantial work has been done in the study of the dynamic compression of cellular materials [11-15], the mechanical response of structural rigid foams subjected to low velocity impact has not been studied in detail. In fact, this problem has received little attention in contrast to sandwich structures although the low velocity impact usually has a significant deteriorating effect on the load-bearing capacity of the foam structure [16]. Additionally, most of the research on the low velocity impact of the foam is limited to hemi-spherical impactors which do not always represent the shape of foreign impacting objects. 
Penetration and perforation in polymeric foams by non-deformable impactors depends mainly on the impact velocity, material properties of the target and geometry of the impactor, e.g., nose shape and diameter. Although, the effect of the impactor nose shape on sandwich panels has been widely studied [7, 17], there is limited research for the same effect on structural polymeric foams.

Low velocity impact with spherical impactors has been studied for aluminium honeycombs targets by Shitta-Bey et al. [18], in which, it was found that the impact load increases with the increase of the impact velocity for a given density, and with the increase of the density for a given impact velocity. The responses of PVC panels impacted by a spherical impactor have been carried out by Rizov [16]. It was found that the impact force increases with the increase of the impact velocity/energy. It was also reported in [16] that the maximum force for a given impact energy is higher for specimens with higher density. The effect of the impact velocity on polystyrene foams for hemi-spherical impactors has been studied by Mills and Moosa [19]. They found that the forcedisplacement curves did not show differences for different impact velocities.

Since a lack of knowledge in the study of the nose shape effect on responses of polymeric foams under low velocity impact has been identified, the present paper addresses this problem through a study of the penetration behaviour of two PMI foams under a range of low velocity impacts from 4 to $8 \mathrm{~m} / \mathrm{s}$ with conical, truncated-conical, flat and spherical nose impactors. An analytical model is developed to predict the penetration behaviour of PMI foams under low velocity impact [20]. A method for processing the experimental measurements of the impact force is also described in order to minimise the effect of noise, which is inherent in all impact measurements.

\section{EXPERIMENTS}

\subsection{Materials}


Commercially available high performance structural polymeric foams Rohacell WF were used in this investigation, which include Rohacell 51WF and 110WF with densities of 52 and 110 $\mathrm{kg} / \mathrm{m}^{3}$, respectively [2].

\subsection{Low velocity impact tests}

Low velocity impact tests were performed on Rohacell WF foams using the impact rig shown in Fig. 1. Impactors \#1-6 (Table 1) were used for impact tests. Impactors were dropped from 1, 2, 3 and $4 \mathrm{~m}$ heights using a vertical guiding tube with a releasing mechanism (Fig. 1). A piezoelectric accelerometer (Kistler model 8602A501) was attached to the impactors. The accelerometer was connected to a signal amplifier with a $100 \mathrm{kHz}$ low-pass built-in electrical filter, which is sufficient for the measurement of the deceleration of the impactor. For impact tests, Rohacell WF foams were cut into $100 \times 100 \times 100 \mathrm{~mm}$ cubes. Specimens were placed on a steel plate. The displacement and the deceleration of the projectile during the impact were measured using a non-contacting optical displacement measurement system (Zimmer 100F) and the attached accelerometer.

The impact velocity was estimated according to the free fall formula, $v=\sqrt{2 g h}$, where $g$ is the gravitational constant and $h$ is the drop height (Table 2). The impact velocity was also measured using Zimmer 100F (Table 2). The difference between the calculated and measured velocities, which increases with drop height, as shown in Table 2, can be attributed to two factors, i.e., the friction between the guiding tube and the impactor during free fall and the small tension of the coaxial cable connecting the accelerometer to the signal amplifier.

Optimal filtering of the dynamic measurements is a difficult issue since a compromise between truncating the real signal and eliminating noise needs to be made [21]. Figure 2 shows the original signal from the accelerometer in a test of a Rohacell 110WF specimen impacted by impactor \#2, which was dropped from a $1 \mathrm{~m}$ height. It can be seen that the signal from the accelerometer contains noise with many high-frequency components, which do not represent the deceleration of the impactor. Therefore, a filtering scheme is needed. 
Table 1 Impactor geometries

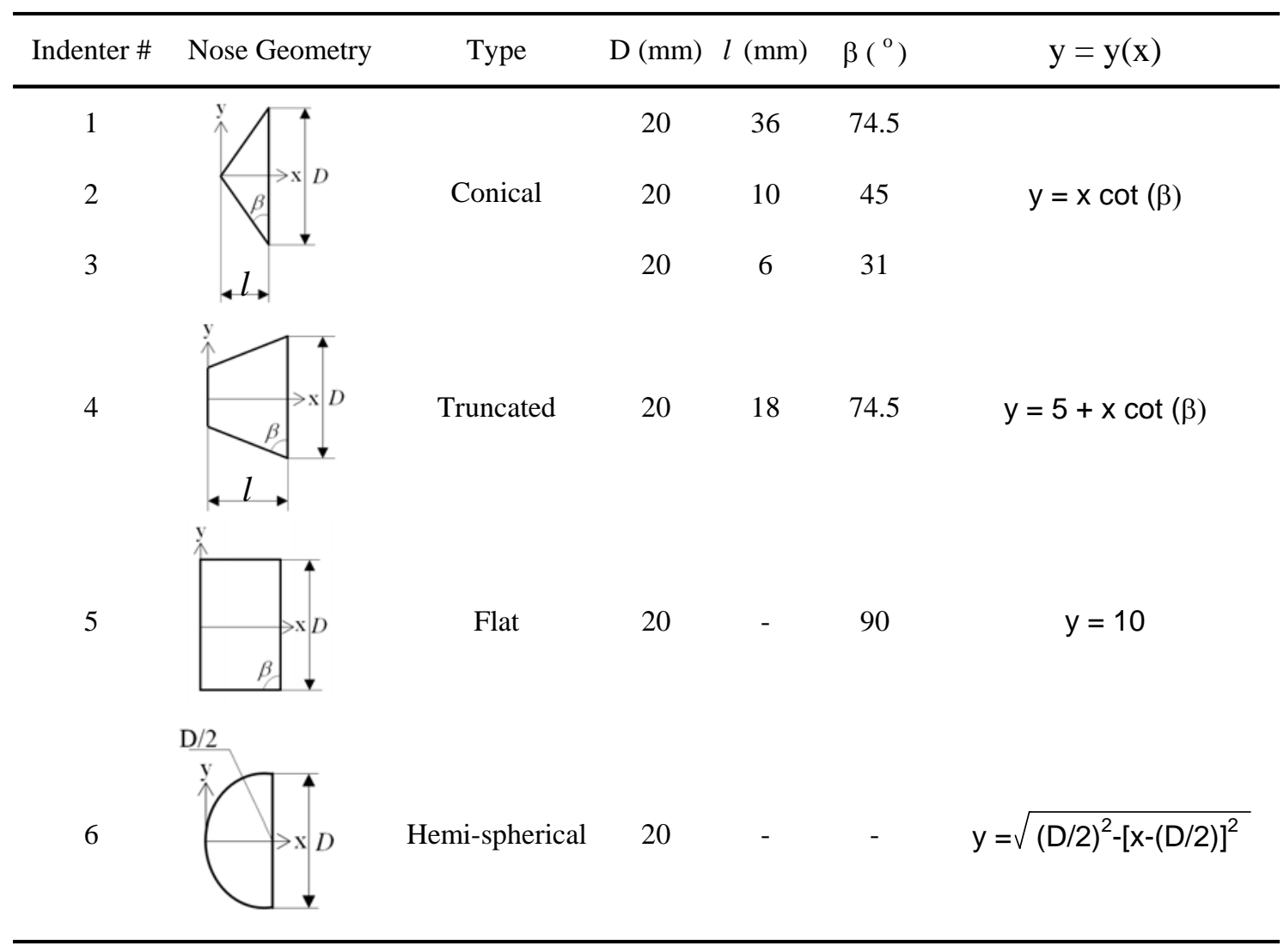

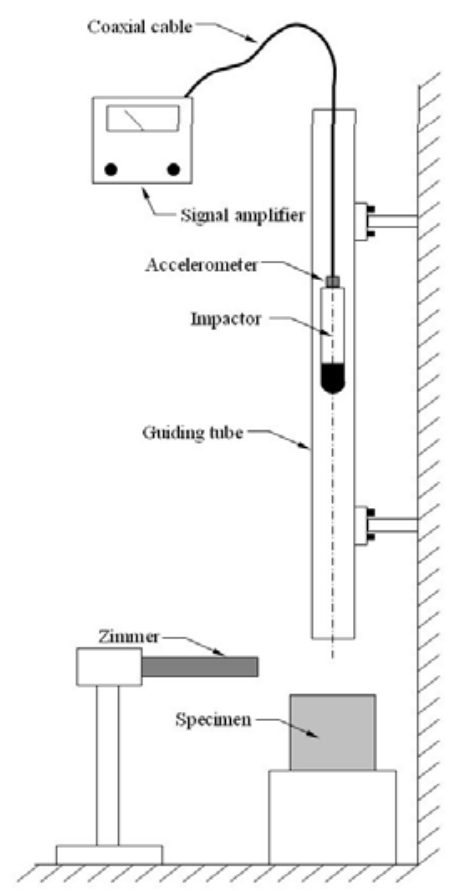

Fig. 1 Low velocity impact test set-up 
Table 2 Calculated and measured velocities for different drop heights

\begin{tabular}{ccc}
\hline Drop Height $(\mathrm{m})$ & Calculated Velocity $(\mathrm{m} / \mathrm{s})$ & Measured Velocity $(\mathrm{m} / \mathrm{s})$ \\
\hline 1 & 4.43 & 4.15 \\
2 & 6.26 & 5.70 \\
3 & 7.67 & 6.45 \\
4 & 8.86 & 7.93 \\
\hline
\end{tabular}

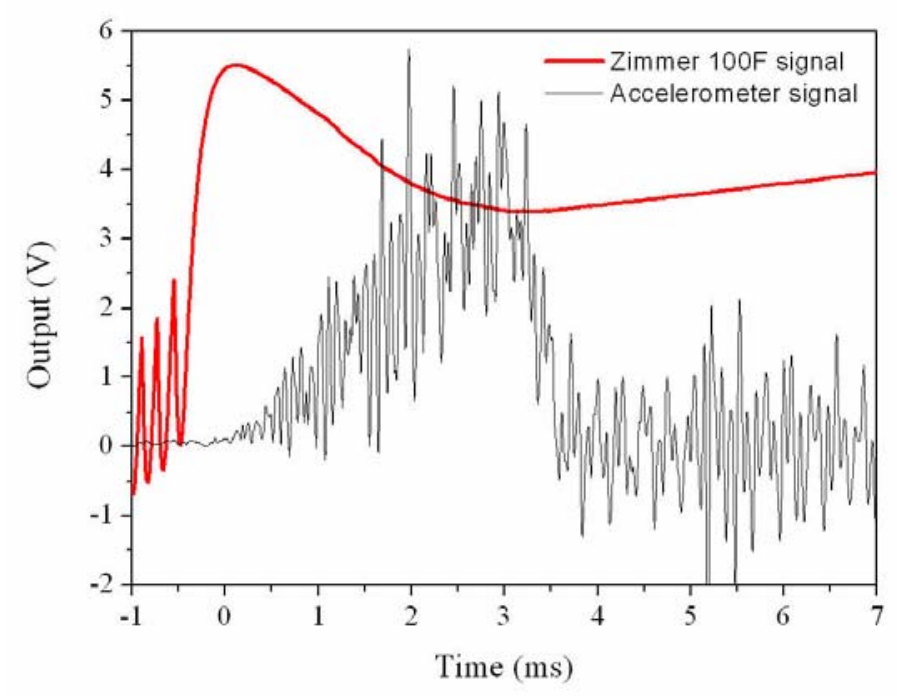

Fig. 2 Original signals of the accelerometer and Zimmer 100F

A method used by Lifshitz et al. [22] and Hernandez [23] to identify the frequencies of the system before the impact and the natural frequencies of the impactor is employed. Figure 3a shows the PSD of the original signal from Fig. 2 and Fig. 3b shows the PSD of the same signal before the impactor hits the specimen. Strong peaks of the frequencies of $1.5 \mathrm{kHz}, 3.8 \mathrm{kHz}, 10.4 \mathrm{kHz}, 12.7$ $\mathrm{kHz}, 17 \mathrm{kHz}$ and $20 \mathrm{kHz}$ were identified. These frequency peaks can be attributed to the natural frequencies of the impactor, the frequencies from the interaction between the impactor and the guiding tube or the frequencies of the environmental noise.

In order to obtain the natural frequencies of the impactor, the impactor with the accelerometer attached was supported by a low density foam and tapped both horizontally and vertically. Figure 4 shows the normalized PSD of the signal from the accelerometer excited by tapping. Four very strong characteristic frequencies can be identified, i.e., 1.5, 3.9, 10.4 and $12.3 \mathrm{kHz}$, which are very similar to the frequencies that were indentified in Fig. 3. This procedure was used for all impactors and similar frequencies were identified for all of them. 
After the frequency analysis, a $3.5 \mathrm{kHz}$ low pass digital filter together with a 1.4-1.6 kHz bandstop digital filter were applied to all accelerometer signals. Figure 5 shows the original signal from Fig. 2 and the filtered signal obtained after applying the above-mentioned digital filters.

It should be noted that the Zimmer 100F does not interact with measured object and has high response frequency (250 kHz), and therefore, the displacement signal (see Fig. 2) is used directly without filtering.

Based on the filtered accelerometer signals, the impact force can be determined by $F=m a ̂$ where $m$ is the mass of the impactor and $\hat{a}$ is the deceleration measured by the accelerometer after the above-mentioned filtering procedures.

The force-time history from filtered accelerometer signal and the displacement-time history from Zimmer 100F are used to obtain the force-penetration curve.
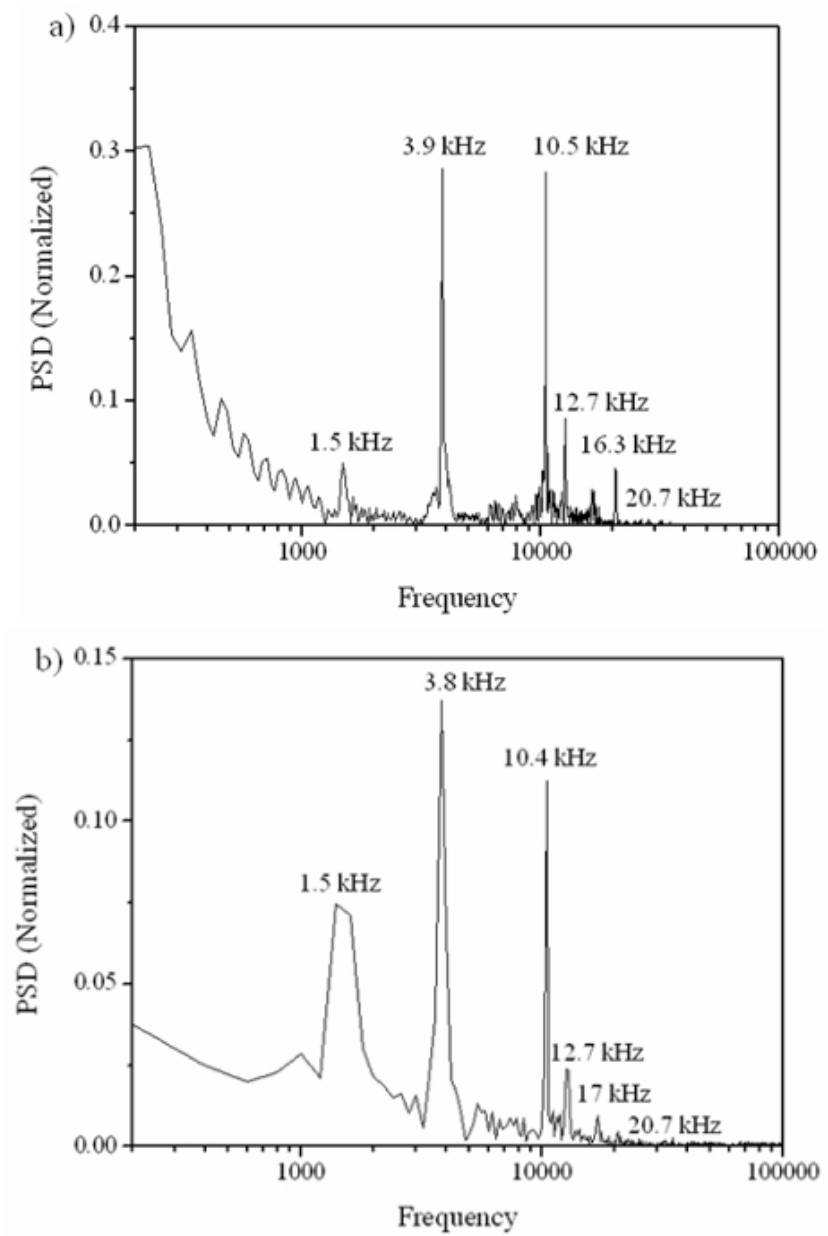

Fig. 3 a) PSD of the original signal in Fig. 2, b) PSD of the original signal in Fig. 2 before impact 

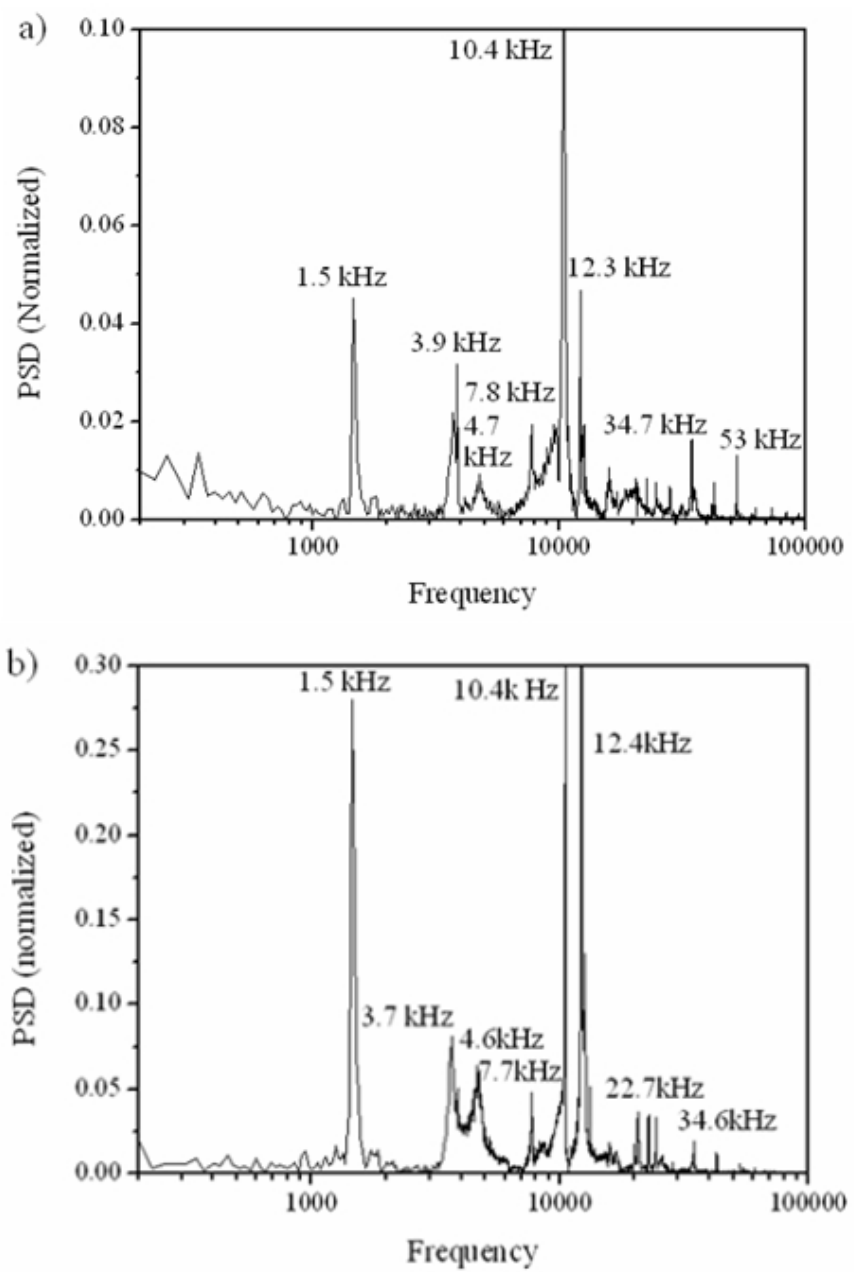

Fig. 4 Normalized PSD from a) vertical tapping and b) horizontal tapping

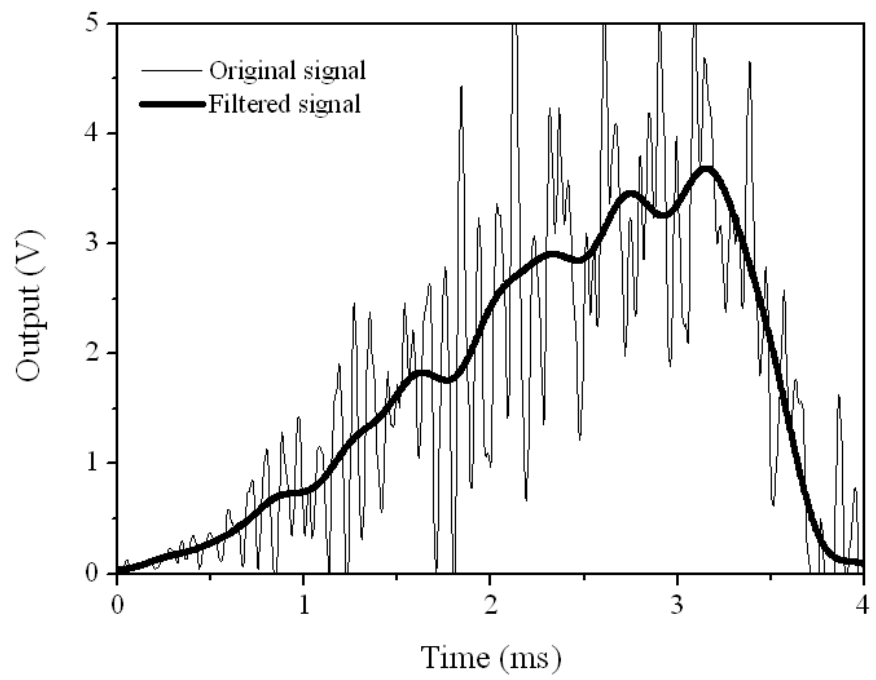

Fig. 5 Comparison between unfiltered and filtered signal from Fig. 2 
Typical force-penetration curves of Rohacell WF foams from different drop heights tested with impactors \#1-6 are depicted in Figs. 6-11, in which quasi-static indentation curves [20] are presented for comparison purpose.

For both Rohacell 51WF and 110WF, the penetration force was found to be dependent on the impactor nose shape. Two distinct regimes were observed, i.e. the initial immersing regime when the nose of the impactor gradually immerse into the foam and the plateau-like regime starting from the moment when the impactor nose has completely immersed into the foam. For all types of impactors, the penetration force was found to be dependent on the density of the foam.

For Rohacell 51WF foam, it can be seen that the dependency of the force-penetration curve on the impact velocity is not significant in the low velocity range (4-8 m/s). However, a dynamic effect can be clearly observed from the impact force-penetration curves, which is consistently below the quasi-static force-penetration curve. Careful examinations of the impacted specimens were performed and compared with those from quasi-static indentation [20]. Cross-sectioned specimens of Rohacell 51WF impacted with impactors \#4 and \#6 are shown in Fig. 12. It is noticed that the crushed zone beneath the impactor is smaller than the crushed zone in quasi-static indentation. The difference between impact and indentation responses can be attributed to the reduced resistance of the impactor-crushed zone. In other words, the bluntness of the crushed zone in quasi-static indentation is higher than that in impact test, which causes the increase of resistance.

For Rohacell 110WF, an increase in the impact force can be observed when it is compared with the resistant force in quasi-static indentation. A slight increase in the impact force with impact velocity was also observed. These observations may be attributed to the enhanced yield stress due to strain rate effects in the strain rate range used in the low velocity impact tests of Rohacell WF specimens, which is estimated as $40-80 \mathrm{~s}^{-1}$ at the start of foam crushing. 

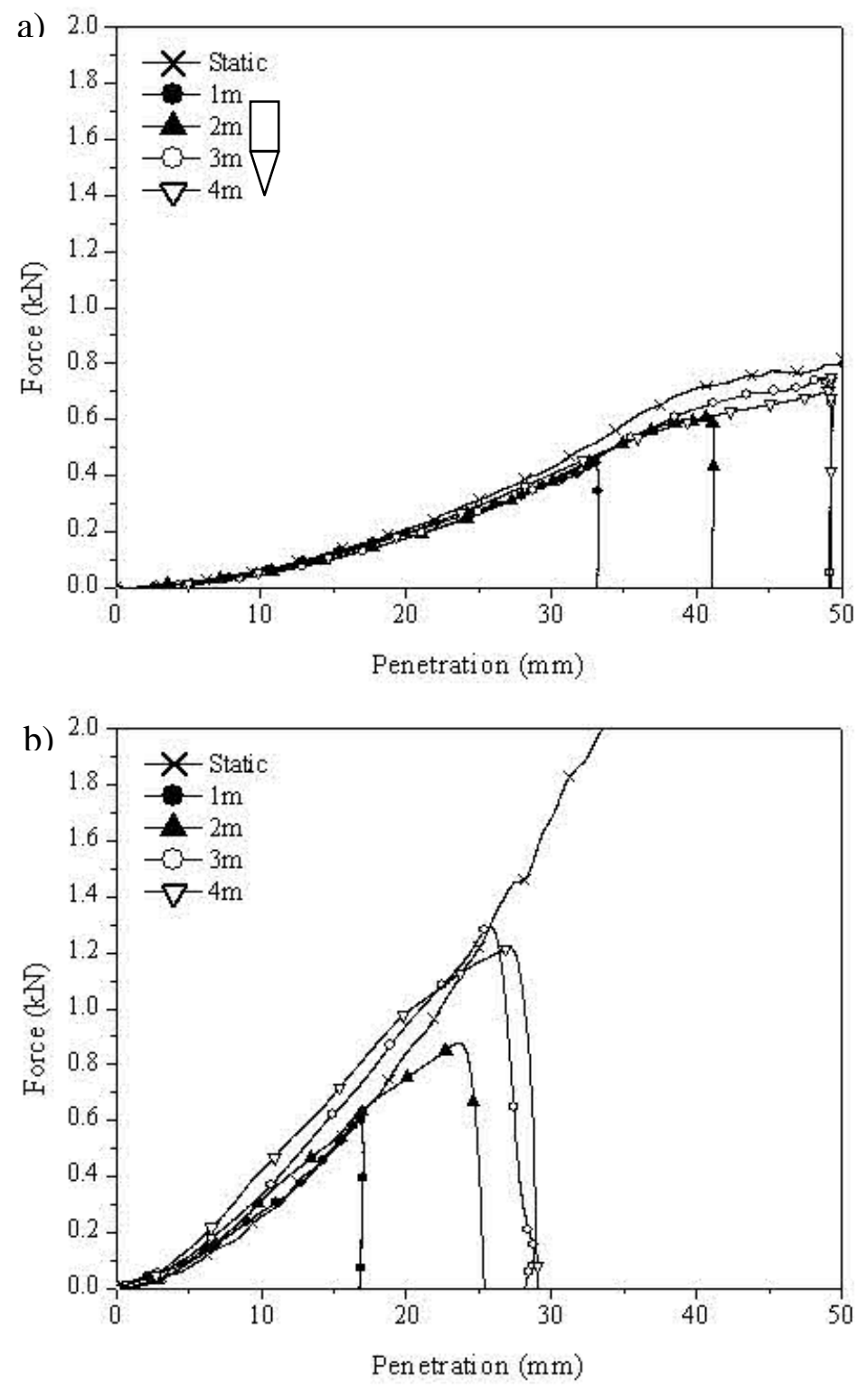

Fig. 6 Force-Penetration curves with impactor \#1 for: a) Rohacell 51WF, b) Rohacell 110WF

Strain rate effects on the compressive yield stress have been observed for Rohacell 51WF in the strain rate range of $10^{-3} \mathrm{~s}^{-1}-10^{2} \mathrm{~s}^{-1}$ by Li et al. [4]. They reported an increase of the compressive yield stress from $\sigma_{P}=0.8 \mathrm{MPa}$ at quasi-static strain rate to $\sigma_{P E}=0.98 \mathrm{MPa}$ at strain rate of $10^{0} \mathrm{~s}^{-1}$. They also reported that the enhanced yield stress remains constant ( $\left.\sigma_{P E}=0.98 \mathrm{MPa}\right)$ in the strain rate range of $10^{0} \mathrm{~s}^{-1}-10^{2} \mathrm{~s}^{-1}$. It is believed that the strain rate effects are also present in the low velocity impact tests of Rohacell 51WF in the present study. However, the reduced resistance due to the reduction of the bluntness of the crushed zone beneath the impactor plays more important role that strain rate effect, which does not allow the observation of strain rate effect in these tests. 

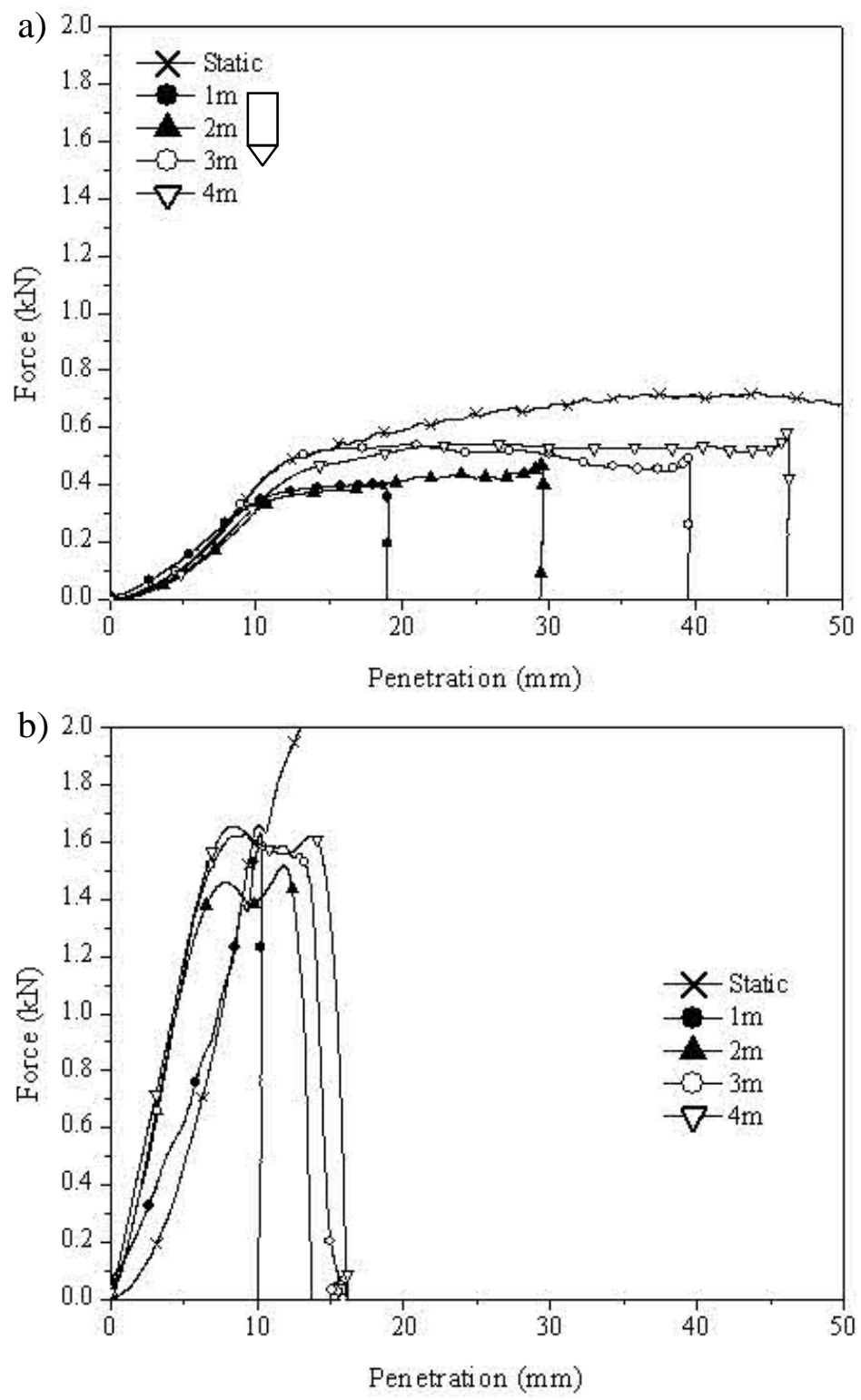

Fig. 7 Force-Penetration curves with impactor \#2 for: a) Rohacell 51WF, b) Rohacell 110WF

Confinement effects due to the increase of foam density may also contribute to the slight increase in the impact force for Rohacell 110WF specimens. The increased density of Rohacell 110WF implies the increased cell interactions, which increase the lateral stresses due to the increased restrictions of the lateral deformation in the specimens and thus, the impact force. The increases of Young's modulus and yield stress due to lateral confinement have been observed by Song et al. [24] for epoxy syntactic foams. It is believed that confinement effects are not significant for low density foam Rohacell 51WF, but its effects increase with increase of foam density. 

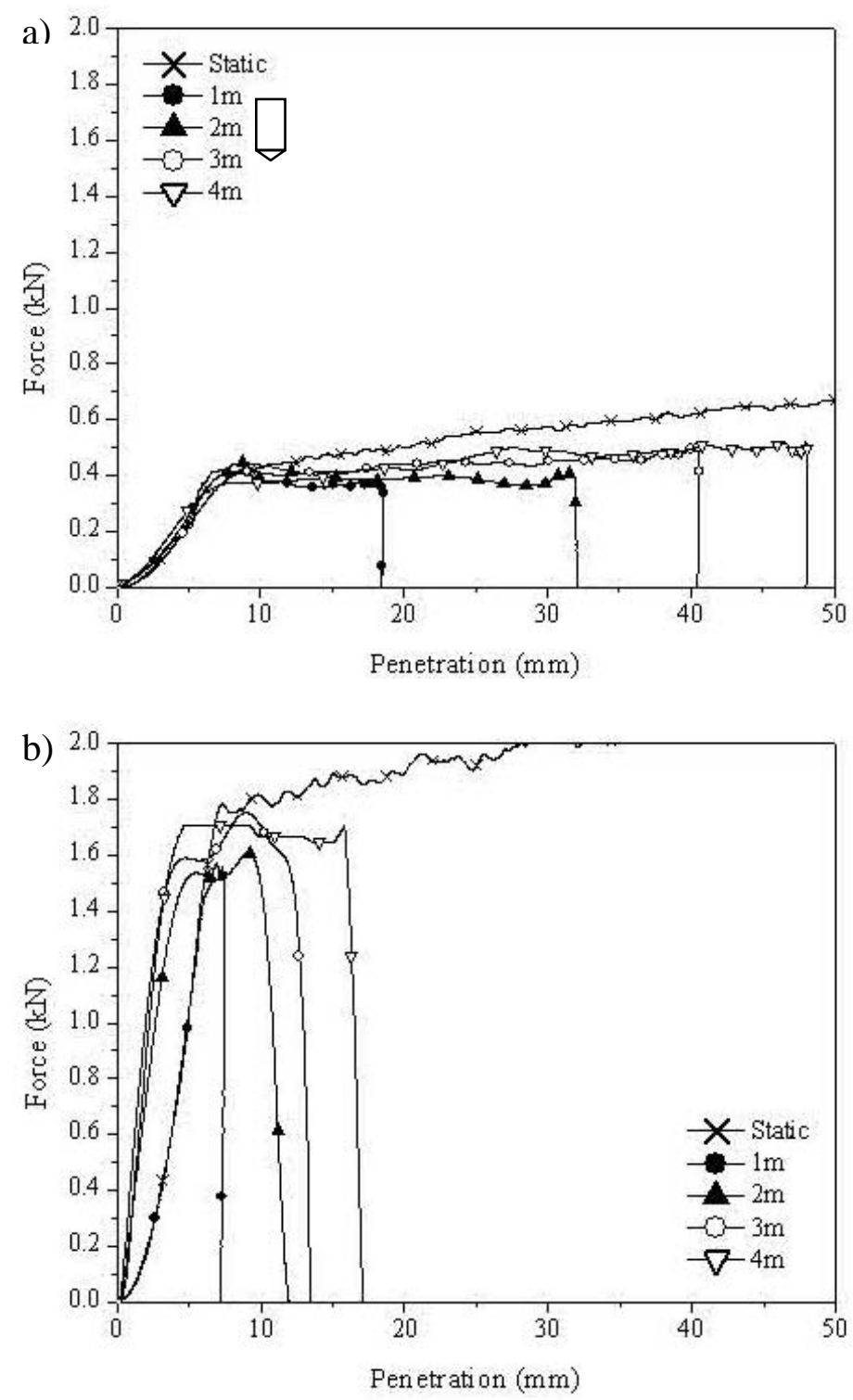

Fig. 8 Force-Penetration curves with impactor \#3 for: a) Rohacell 51WF, b) Rohacell 110WF

\section{DISCUSSION}

\subsection{Penetration resistance}

Based on the indentation tests on polymeric foams, an analytical model to predict the indentation resistance force was developed for an impactor with given nose shape $y=y(x)$ [20]. The total resisting force $F_{R}$ during the immersing stage of the indenter nose consists of the crushing force, the tearing force and the friction force. It was also observed that, after the complete immersion of the indenter nose, there is friction traction between the indenter body and the foam. 

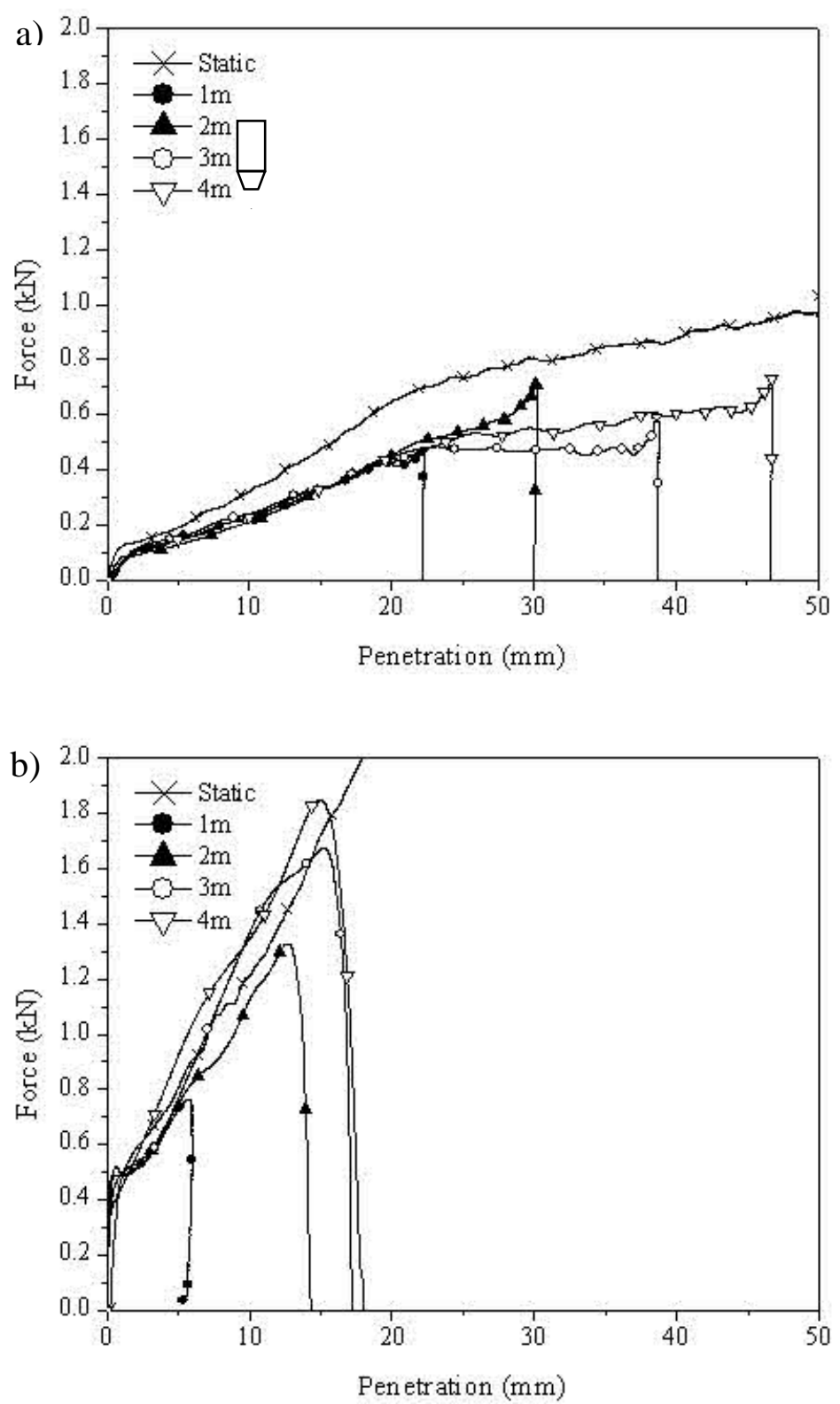

Fig. 9 Force-Penetration curves with impactor \#4 for: a) Rohacell 51WF, b) Rohacell 110WF

The total resisting force $F_{R}$ during the immersing stage of the indenter nose and after the complete immersion of the indenter nose can be expressed as [20]

$$
\begin{aligned}
& F_{R}=2 \pi \int_{0}^{z}\left(y y^{\prime} \sigma_{y}+\mu_{C} \sigma_{y} y+\Gamma y^{\prime}\right) d x \quad(0 \leq z \leq l) \\
& F_{R}=2 \pi\left[\int_{0}^{l}\left(y y^{\prime} \sigma_{y}+\mu_{C} \sigma_{y} y+\Gamma y^{\prime}\right) d x+a(\mu p)(z-l)\right](z>l)
\end{aligned}
$$

where $z$ is the indentation depth, $l$ is the length of the nose, $\Gamma$ is the tearing energy per unit area [25], $\sigma_{y}$ is the yield stress and $\mu_{C}$ is the coefficient of friction. The term $(\mu p)$ is the friction traction 
per unit area between the foam wall and the body of the impactor after the nose has completely immersed into the foam. These values for Rohacell 51WF and 110WF will be given later. Eqs. (12) developed for quasi-static indentation, can be use to predict the impact response if the yield stress is substituted by the enhanced yield stress due to strain rate effects and penetration mechanisms observed in low velocity impact tests are incorporated in the formulas.
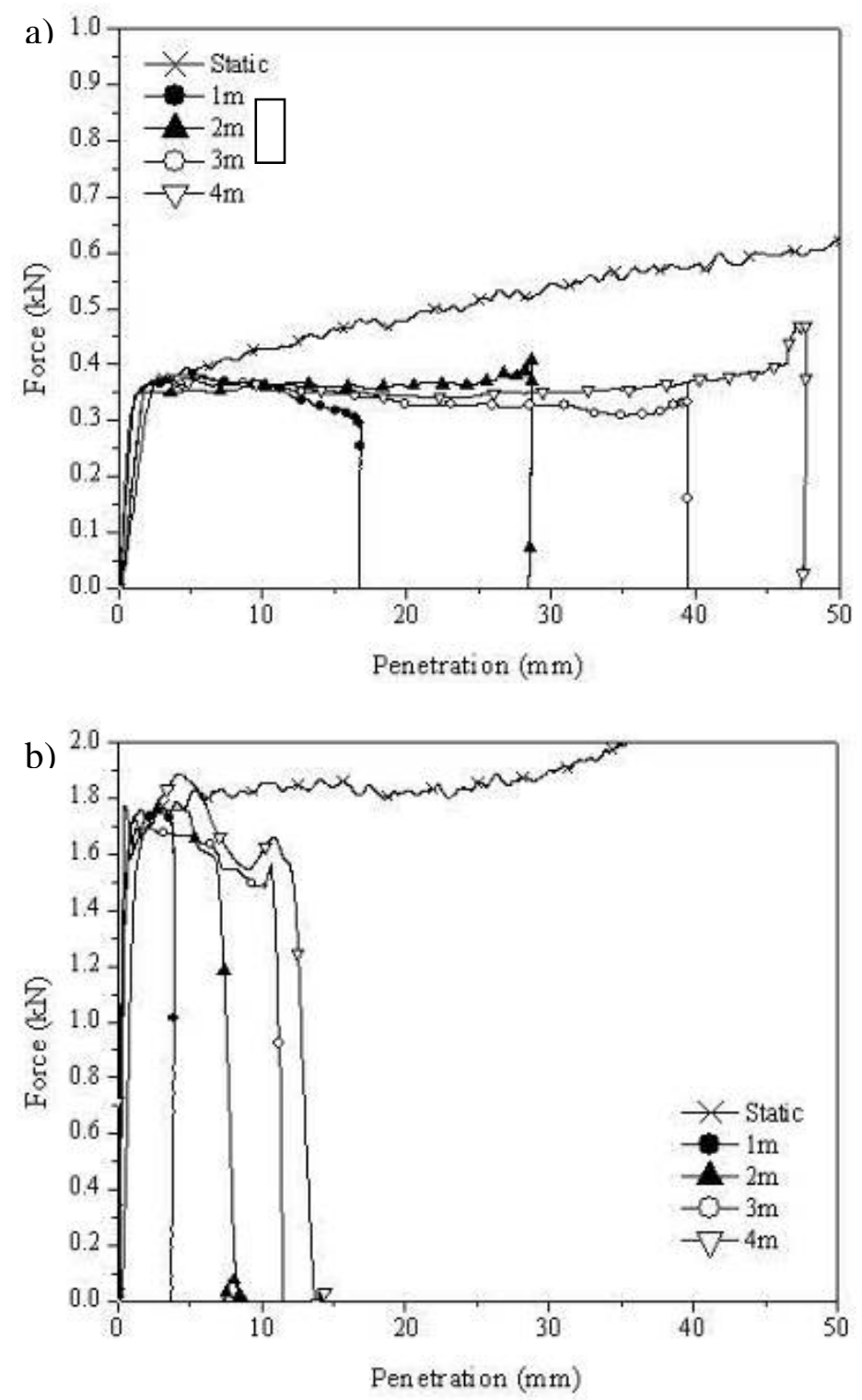

Fig. 10 Force-Penetration curves with impactor \#5 for: a) Rohacell 51WF, b) Rohacell 110WF 

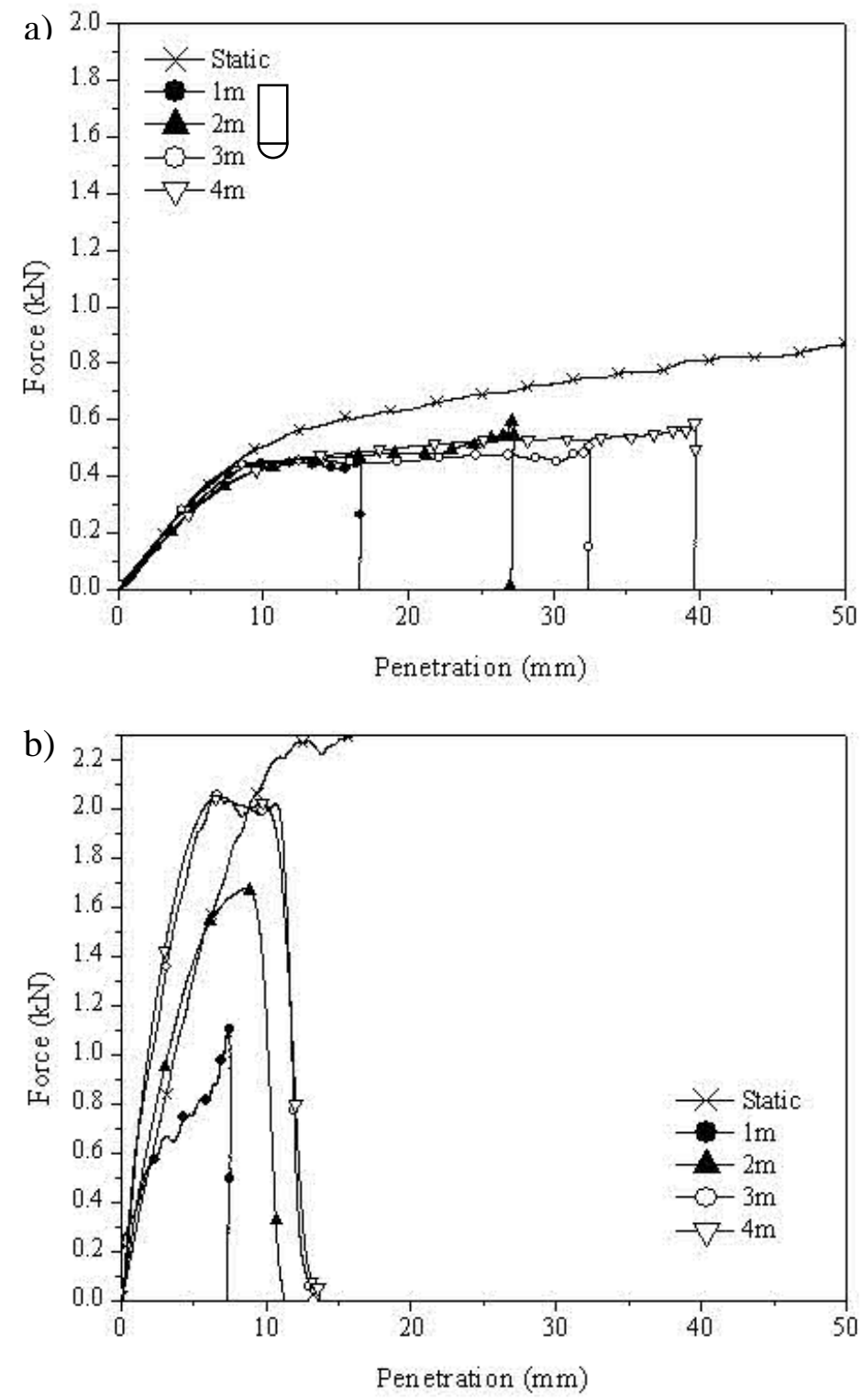

Fig. 11 Force-Penetration curves with impactor \#6 for: a) Rohacell 51WF, b) Rohacell 110WF
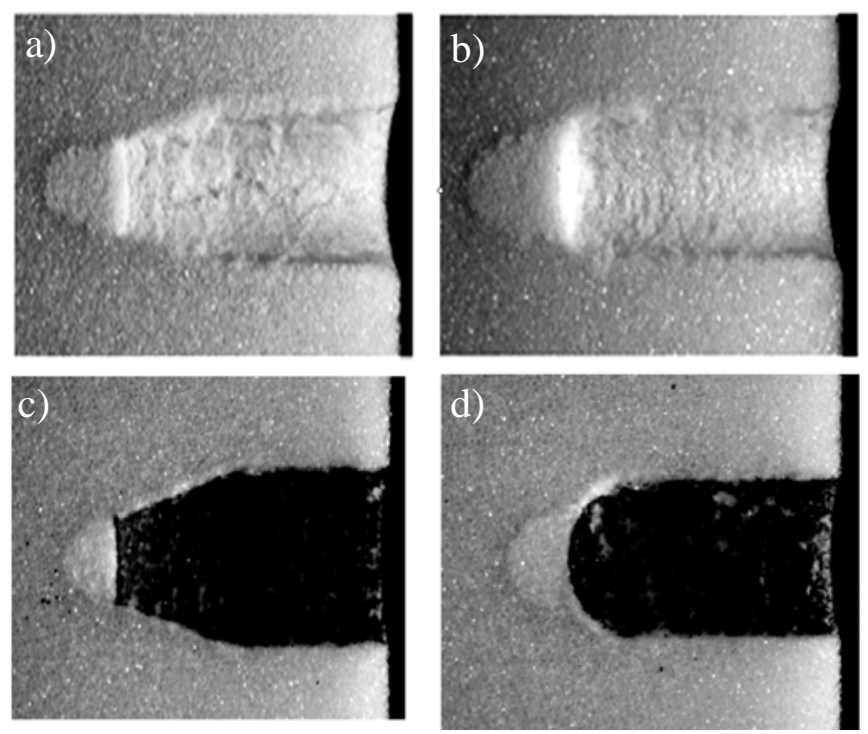

Fig. 12 Cross-section of the indented Rohacell 51WF specimens with impactor \#4; (a) quasi-static, (c) impact; with impactor \#6: (b) quasi-static, (d) impact. 
For Rohacell 51WF, a dynamic effect, was noted (i.e., the impact response curve is below the quasi-static response curve (Figs. 6-11)), which is independent of the impact velocity. The difference between impact and indentation responses can be attributable to the reduced resistance by the impactor-crushed zone, i.e., the bluntness of the frontal crushed zone in impact test is smaller than that in a quasi-static indentation test. During the advance of the impactor in foam medium, a crushed zone is formed, which changes the bluntness of the nose of the impactor. Thus, Eqs. (1-2) should be multiplied by a bluntness factor BF.

For Rohacell 110WF, the dynamic effect observed for Rohacell 51WF was not observed. However, a slight increase of load with the increase of impact velocity was observed suggesting that the impact velocity has an effect on the yield stress of the material. Due to the lack of strain rate sensitivity study for Rohacell $110 \mathrm{WF}$, the dynamic yield stress is estimated as $\sigma_{P E}=4.2 \mathrm{MPa}$ in the formulas, which gave the best agreement between predictions and experiments.

Figure 13 shows the impact experimental results along with predictions from Eqs.(1-2) using a value of $B F=0.9$ for Rohacell 51WF. Nose shape functions used for all the impactors are shown in Table 1. Values of $\sigma_{P E}=0.98 \mathrm{MPa}$ [4], $\Gamma=1.39 \mathrm{~kJ} / \mathrm{m}^{2}, \mu p=0.094 \mathrm{MPa}$ [20] and $\varepsilon_{D}=0.69$ [6] were used for Rohacell 51WF and $\sigma_{P E}=4.2 \mathrm{MPa}, \Gamma=5.64 \mathrm{~kJ} / \mathrm{m}^{2}, \mu p=0.115 \mathrm{MPa}$ [20] and $\varepsilon_{D}=0.65$ [6] for Rohacell 110WF.

In general, good agreements are observed for all impactors between experimental and analytical predictions for Rohacell 51WF. For Rohacell 110WF, predictions reasonably agree with experimental results for the lowest impact velocity (1 $\mathrm{m}$ drop height). For the highest impact velocity (4 m drop height), good predictions of the maximum load can be observed, except for impactor \#1 where the maximum load is overestimated. It can be observed in Fig. 13 that the stiffness increases slightly with impact velocity for Rohacell 110WF and $4 \mathrm{~m}$ drop height which is not predicted by the model. This observation can be attributed to various deformation mechanisms (e.g. micro inertia of the cells [14]) which are not considered by the model. 

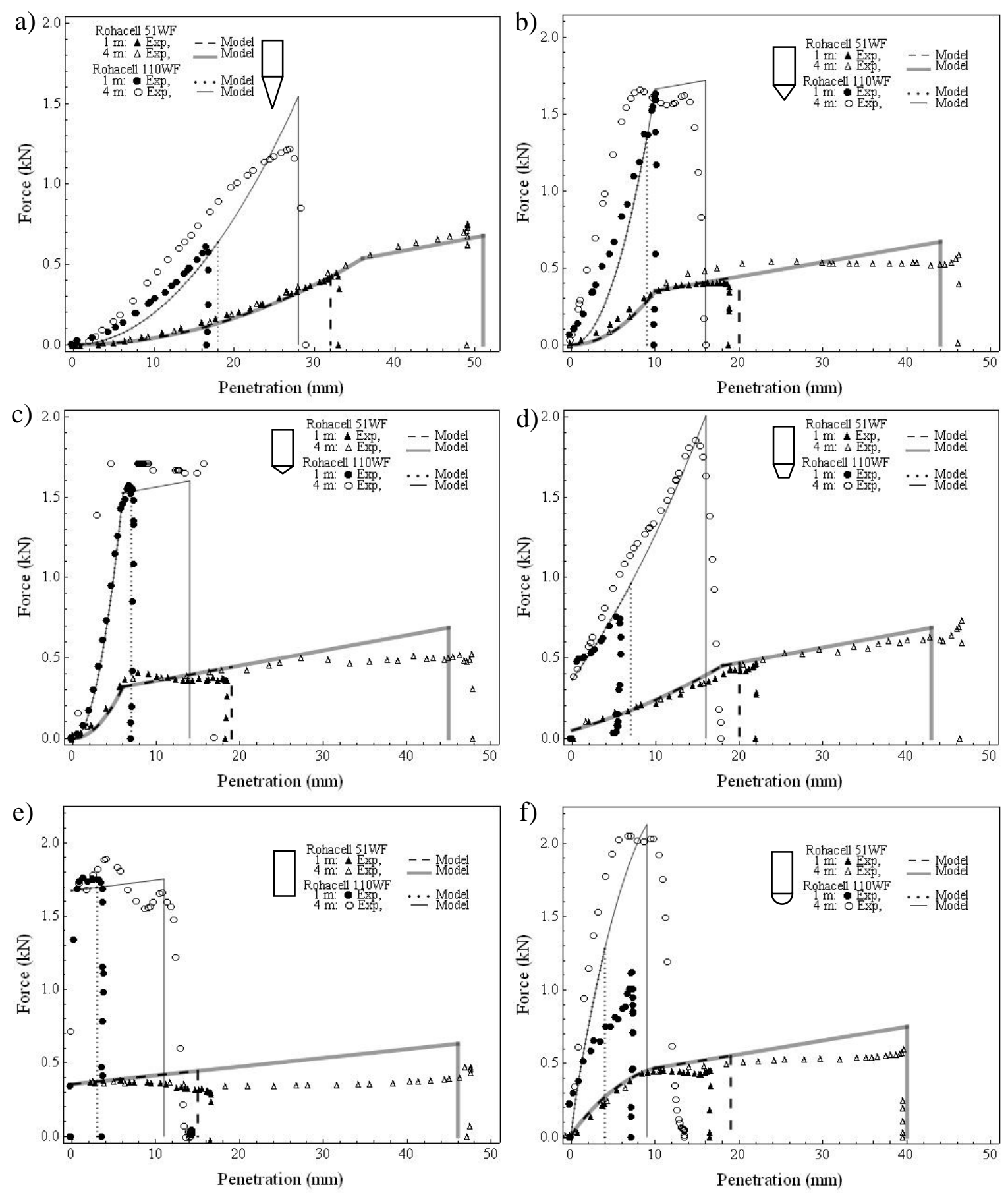

Fig. 13 Experimental and predicted results of the penetration force for Rohacell 51WF and 110WF with impactors: a) $\# 1$, b) \#2, c) \#3, d) \#4, e) \#5, f) \#6

The use of the enhanced dynamic yield stress $\sigma_{P E}=0.98 \mathrm{MPa}$ and $\sigma_{P E}=4.2 \mathrm{MPa}$ in the model for Rohacell 51WF and 110WF, respectively, gave reasonably good predictions of the forcepenetration curves. However strain rate and confinement sensitivity studies for Rohacell 110WF 
foam, which are unavailable in the present study, need to be performed in order to validate the value of $\sigma_{P E}=4.2 \mathrm{MPa}$ used in this research.

\section{CONCLUSIONS}

It is shown in low velocity impact tests that penetration force depends on the geometry of the impactor and the density of the foam. In the low impact velocity range studied in this research, the effect of the impact velocity on the penetration resistance load is not observed for Rohacell 51WF. However, a dynamic effect is identified, i.e., the impact resistance is lower than quasi-static indentation resistance. This is due to the reduction of the crushed zone beneath the impactor in impact. For Rohacell 110WF, a slight increase of the resistance force with the increase of impact velocity is observed, which is attributed to the increased strain rate and confinement effects for higher density foams.

Analytical models based on experimental observations are proposed to predict the penetration resistance. Parameters in these analytical models have clear physical meanings and can be determined by material tests. Good agreement is observed between analytical predictions and experimental results for both Rohacell 51WF and 110WF foams.

Acknowledgments: Rohacell WF foams were supplied by Evonik Röhm GmbH \& Co. E.A. Flores-Johnson was sponsored by the Mexican Government (CONACYT scholarship No. 172677).

\section{REFERENCES}

1. Abrate S, Impact on Composite Structures. 1998, New York: Cambridge University Press.

2. EVONIK Röhm GmbH Data CD ‘ROHACELL® - The Core for Sandwich Solutions’, April 2008.

3. Li QM, Magkiriadis I, Harrigan JJ (2006) Compressive strain at the onset of densification of cellular solids. Journal of Cellular Plastics. 42(5): p. 371-392. 
4. Li QM, Mines RAW, Birch RS (2000) The crush behaviour of Rohacell-51WF structural foam. International Journal of Solids and Structures. 37(43): p. 6321-6341.

5. Li QM, Mines RAW (2002) Strain measures for rigid crushable foam in uniaxial compression. Strain. 38(4): p. 132-40.

6. Flores-Johnson EA, Li QM, Mines RAW (2008) Degradation of Elastic Modulus of Progressively Crushable Foams in Uniaxial Compression. Journal of Cellular Plastics. 44(5): p. 415-434.

7. Sun CT, Wu CL. Low Velocity Impact of Composite Sandwich Panels. in Proc 32th AIAA/ASME/ASCE/AHS/ASC Structures, Structural Dynamics and Materials Conf. 1991. Baltimore.

8. Rizov V, Shipsha A, Zenkert D (2005) Indentation study of foam core sandwich composite panels. Composite Structures. 69(1): p. 95-102.

9. Chen CP, Anderson WB, Lakes RS (1994) Relating the properties of foam to the properties of the solid from which it is made. Cellular Polymers. 13(1): p. 16-32.

10. Chen CP, Lakes RS (1995) Analysis of the structure-property relations of foam materials. Cellular Polymers. 14(3): p. 186-202.

11. Hanssen AG, Hopperstad OS, Langseth M, Ilstad H (2002) Validation of constitutive models applicable to aluminium foams. International Journal of Mechanical Sciences. 44(2): p. 359-406.

12. Harrigan JJ, Reid SR, Reddy TY. Inertial effects on the crushing strength of wood loaded along the grain. in Experimental Mechanics: Advances in Design, Testing and Analysis : Proceedings of the 11th International Conference on Experimental Mechanics. 1998. Oxford: A.A. Balkema.

13. Maji AK, Schreyer HL, Donald S, Zuo Q, Satpathi D (1995) Mechanical Properties of Polyurethane-Foam Impact Limiters. Journal of Engineering Mechanics. 121(4): p. 528-540.

14. Mines RAW (2007) Strain rate effects in crushable structural foams. Applied Mechanics and Materials. 7-8: p. 231-236.

15. Zhang J, Kikuchi N, Li V, Yee A, Nusholtz G (1998) Constitutive modeling of polymeric foam material subjected to dynamic crash loading. International Journal of Impact Engineering. 21(5): p. 369-386.

16. Rizov VI (2007) Low velocity localized impact study of cellular foams. Materials \& Design. 28(10): p. 2632-2640.

17. Wen HM, Reddy TY, Reid SR, Soden PD (1998) Indentation, Penetration and Perforation of Composite Laminate and Sandwich Panels under Quasi-Static and Projectile Loading. Key Engineering Materials 141-143 p. 501-552.

18. Shitta-Bey OT, Carruthers JJ, Soutis C, Found MS (2007) The localized low-velocity impact response of aluminium honeycombs and sandwich panels for occupant head protection: experimental characterization and analytical modelling. International Journal of Crashworthiness. 12(5): p. 549 - 558. 
19. Mills NJ, Moosa ASI (1999) Impacts of Hemispherical Strikers on Polystyrene Bead Foam. Journal of Cellular Plastics. 35(4): p. 289-310.

20. Flores-Johnson EA, Li QM (2009) Indentation into polymeric foams. Submitted to International Journal of Solids and Structures.

21. Li QM, Mines RAW, Birch RS (2001) Static and dynamic behaviour of composite riveted joints in tension. International Journal of Mechanical Sciences. 43(7): p. 1591-1610.

22. Lifshitz JM, Gov F, Gandelsman M (1995) Instrumented low-velocity impact of CFRP beams. International Journal of Impact Engineering. 16(2): p. 201-215.

23. Hernández W (2001) Improving the response of an accelerometer by using optimal filtering. Sensors and Actuators A: Physical. 88(3): p. 198-208.

24. Song B, Chen W, Yanagita T, Frew DJ (2005) Confinement effects on the dynamic compressive properties of an epoxy syntactic foam. Composite Structures. 67(3): p. 279-287.

25. Olurin OB, Fleck NA, Ashby MF (2000) Indentation resistance of an aluminium foam. Scripta Materialia. 43(11): p. 983-989. 